\title{
Squamous Cell Carcinoma Ex Pleomorphic Adenoma of the Parotid Gland - A Case Report with Clinicopathological Review
}

\author{
SM KHODEZA NAHAR BEGUM, ${ }^{1}$ M ALAMGI R CHOWDHURY, ${ }^{2}$ AFROZA SURAYA MOJ UMDER, ${ }^{3}$ OMID KHAN ${ }^{4}$
}

\begin{abstract}
:
Pleomorphic adenoma, though essentially benign can undergo malignant transformation. This is the case report of a 72 year old male with a giant tumor of parotid gland measuring 20.0XI8.0X $16.5 \mathrm{~cm}$ \& weighing $7 \mathrm{~kg}$. Pleomorphic adenoma can rarely transform into carcinoma ex pleomorphic adenoma over time as it enlarges; moreover, histologically, squamous cell carcinoma (SCC) is exceedingly rare. Patient developed the tumor for a period over 20 years \& it caused withdrawal from social contact. The tumor gradually enlarged without any pain or other complication except for rapid growth \& pain a year before. Postoperative facial function and local control of tumor was achieved. Despite Of having a cancer with significant extracapsular invasion, our patient did not present any metastatic focus. Besides morphological patterns, authors need to categorize invasive carcinoma ex pleomorphic adenoma according to its potentiality to metastasize. Various parameters which can predict malignant transformation in pleomorphic adenoma is also yet to be explored.
\end{abstract}

Key Word: Pleomorphic adenoma, Squamous cell carcinoma, Salivary gland.

\section{Introduction}

Pleomorphic adenoma (PA) is a being salivary gland neoplasm. It occurs more frequently in women than in man and is most prevalent from the fourth to sixth decades with a mean age of 45 year. ${ }^{1}$ It usually presents as a slow growing and painless swelling. Because of their remarkable histologic diversity, these neoplasms have also been called mixed tumors.

They represent about $60 \%$ of tumors in the parotid, are less common in the submandibular gland and are relatively rare in minor salivary glands. ${ }^{2}$ This tumor is associated with recurrences, malignant transformation and metastasis. ${ }^{3}$ Carcinoma ex pleomorphic adenoma(CXPA) represents malignant transformation of a pre-existing pleomorphic adenoma, usually in the setting of long standing pleomorphic adenoma or in a tumor with multiple recurrences. The incidence ranges from $1.9 \%$ to $23.3 \%$ according to different series. ${ }^{4}$ The risk increases with the duration of the tumor, with an incidence of $9.5 \%$ for tumors present for more than 15 years. ${ }^{5}$ We report a case of CXPA showing all the classical

1. Associate Professor, Department of Pathology, Anwer Khan Modern Medical College, Dhaka.

2. Professor, Department of Otolaryngology - Head \& Neck Surgery, Anwer Khan Modern Medical College, Dhaka.

3. Registrar, Department of Otolaryngology - Head \& Neck Surgery, Anwer Khan Modern Medical College, Dhaka.

4. Intern doctor, Dhaka Medical College \& Hospital, Dhaka.

Correspondence: Dr S M khodeza Nahar Begum. Associate Professor of Pathology, Anwer Khan Modern Medical College, Dhaka. E-mail: khodeza33@hotmail.com. features with abnormally increased size without regional or distant metastasis.

A complete review of this malignant mixed tumor is done with special emphasis on the pathogenic mechanism that leads to transformation of PA to CXPA.

\section{Case Report}

A 72 year old man reported to our hospital with a huge neck mass. The patient gave history of the lesion being present since past 20 years which had gradually increased to the present size. He refused treatment because of fear of surgery till date which caused withdrawal from social contact. He presented this time because of recent onset of pain \& fairly rapid growth of tumor. On examination the mass was found soft to firm in consistency and covered by stretched skin with superficial distended veins. There is surface ulceration at its dependent part. The tumor extended anteriorly from right preauricular region and extended along the length of the neck upto the supraclavicular notch (fig 1 ). The CT scan of the lesion revealed well defined predominantly solid mass $18.6 \mathrm{x}$ $15.2 \mathrm{~cm}$ in size. The mass was seen extending superficially from the preauricular region. Medially tumour had continuation with the right parotid gland. The right carotid sheath and its contents were displaced medially. There was no sign of invasion of surrounding soft tissues. No palpable cervical lymph node was seen. Chest radiograph revealed unremarkable features. 


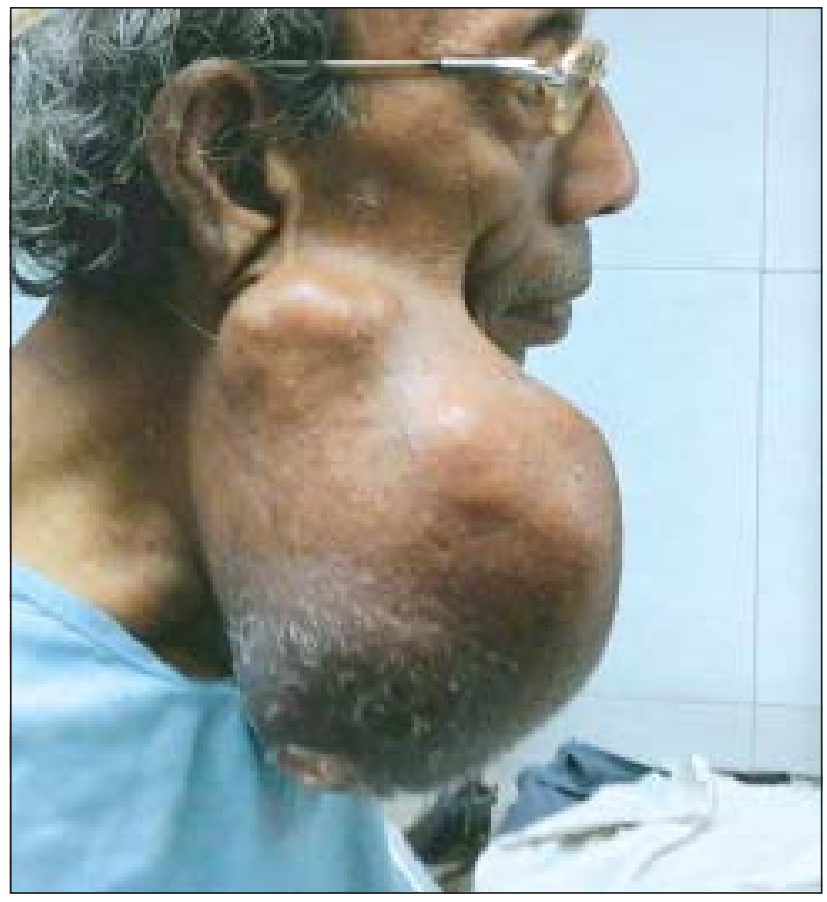

Fig.-1: Huge parotid mass

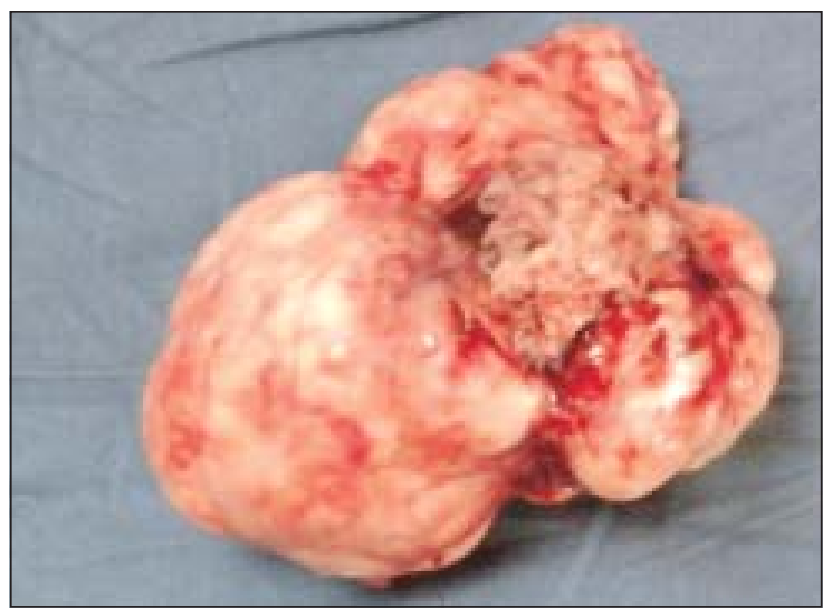

Fig.-2: Excised tumour

Complete surgical excision of the lesion was performed using the cervical trans-parotid approach with preservation of facial nerve. The nerve was gently dissected from the deeper zone of the tumor and the tumour was then completely removed. There was no sign of invasion of surrounding soft tissues. Gross examination revealed a huge pink-tan smooth surfaced lobulated mass with irregular fungating appearance for an area extending for about $6 \mathrm{~cm}$. (Fig - 2). Cut sections show pink-tan predominantly solid areas with wide necrotic zones. Solid areas showed glistening, shiny and pink-tan areas of soft to firm consistency. Areas suggestive of necrosis, hemorrhage and fibrosis are also noticed.
Histopathology showed an epithelial tumour characterized by sheets \& trabeculae of anaplastic squamous cells with cellular pleomorphism, high mitotic count, atypical mitotic figures and focal coagulative necrosis (Fig: 3\&4). Abundant chondromyxoid areas and areas representing parent pleomorphic adenoma are seen at some foci. The tumour showed clear evidences of capsular invasion and skin involvement by the carcinoma cells. No perineural or lymphovascular invasion was seen. A histopathological diagnosis of Squamous cell carcinoma (SCC) ex pleomorphic adenoma; grade 2 was made. Pathological stage was pT4aN0M0.

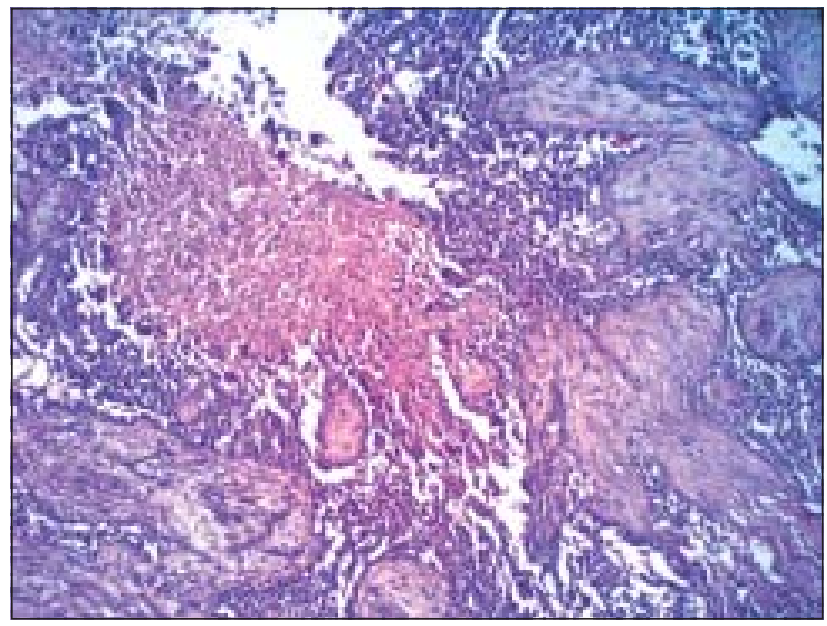

Fig.-3: Squamous cell carcinoma at low power (X10)

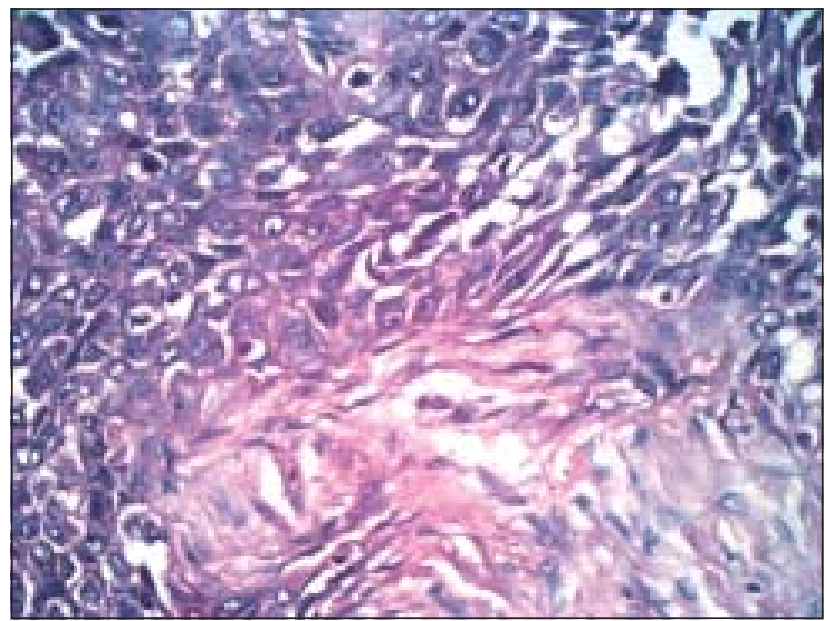

Fig.-4: Tumour at high power (X40)

Patient has undergone PET scan of whole body \& other biochemical investigations in relation his condition. He was referred to an oncologist for further chemo radiotherapy. Full course radiotherapy and chemotherapy was given successfully. He received six cycle chemotherapy and is doing well till date. 


\section{Discussion}

CXPA is a rare, aggressive poorly understood malignancy that usually develop in a primary or recurrent PA. ${ }^{4}$ The cancer usually takes the form of a adenocarcinoma or undifferentiated carcinoma, and often it virtually completely overgrows the preexisting pleomorphic adenoma. Numerous CXPA subtypes have been described in previous reports. ${ }^{6,7}$ It appears that SCC ex pleomorphic adenoma is rare as noted by Peel and Gnepp. $\underline{-}$ In differential diagnosis, it is important to distinguish SCC and squamous cell metaplasia. ${ }^{9,10}$ In the presence of keratin, SCC cells are immunoreactive for AE1/ AE3, whereas ductal epithelial-type cells are usually positive for both AE1/AE3 and CK7 and myoepithelial-type cells are focally positive. ${ }^{11}$ In our case immunohistochemistry was not performed as sheets of anaplastic squamous cells showed unequivocal morphological features characteristic for invasive squamous cell carcinoma. To substantiate the diagnosis of carcinoma ex pleomorphic adenoma, recognizable traces of the latter must be found. Sometimes the origin can only be inferred from history. Histopathological features of CXPA are the capsular invasion, hemorrhage \& necrosis alternating with areas presenting classical features of pleomorphic adenoma. ${ }^{12}$ The tumors predominantly show epithelial component exhibiting malignant transformation as opposed to carcinosarcomas that have both epithelial and connective tissue malignant components. ${ }^{13}$ Malignant transformation may follow a stepwise sequence manifested as follows. ${ }^{5.14}$

1. Carcinoma in situ: The earliest phase where carcinoma cells replace the ductal luminal cells retaining an intact myoepithelial cell layer.

2. Intracapsular carcinoma: Development of stromal invasion by the tumor cells without violation of the capsule.

3. Invasive carcinoma: Extracapsular invasion.

In the present case, the lesion was present since 20 years and rapid growth was noticed past 1 year. It usually presents as a mass with a long evolution that shows a sudden increase in size. In $12-55 \%$ of cases this rapid enlargement may by accompanied by pain, facial nerve palsy and fixation to the surrounding soft tissue. Only a small numbers of patients may have tumors with rapid growth without any symptoms. Our patient presented with pain \& facial never palsy. There was no palpable lymph node in his neck region. His computed tomography \& chest skiagram did not reveal any cervical lymph node enlargement or evidence of any mass lesion in lung field. In the literature, most of the cases are reported to have metastasis into regional lymph nodes. Few cases of gigantic CXPA metastasizing to mediastinal lymph nodes have also been reported ${ }^{15}$. An analysis of 73 cases treated at Mayo clinic done by Lewis et al have revealed that the most significant features of prognosis in CXPA include tumor stage, grade and proportion of carcinoma, extent of invasion \& proliferation index determined by digital image analysis of feulgen \& MIB-1 stained sections respectively ${ }^{16}$. But, using interpretation of cellular atypia, increased mitotic index and lack of encapsulization as prognostic predicator remains controversial. ${ }^{3,7}$ In most cases it is generalized as an imbalance between apoptosis and proliferation of transformed cells.

In addition to the grading, Ki 67, or other proliferation markers are useful prognostic indicators while P53 \& Ecadherin appear to be of limited value. ${ }^{17}$ Our case had significant extra capsular invasion and high histological grade with absence of any metastatic focus. The optimum point to define a category of invasive carcinoma ex pleomorphic adenoma with no or minimal metastatic potential is currently unsettled, but the different findings may reflect difficulties in making reproducible measurements. Also, detailed histopathological examination and application of appropriate biomarkers to PA should enable us discriminate lesions with high risk of malignant transformation from those with low risk.

\section{Conflict of Interest: None}

\section{References}

1. Cristofer D M Fletcher: Tumours of the salivary gland. In: Diagnostic histopathology of tumours. Ed 4; Elsevier, Saunders 2013:277.

2. Robins \& Cotrans: Head \& Neck. In: Pathological basis of diseases. Ed 8, Elsevier 2010:757.

3. Ellis G L, Auclair PL, eds. Malignant epithelial tumours. In: Atlas of tumour pathology. Series 3, section 5, fascicle 17.Washington DC: Armed Forces institute of pathology. 1996:155-373.

4. Auclair PL, Ellis GL. Atypical features in salivary gland tumours; their relationship to malignant transformation. Mod pathol. 1996;9:652-657.

5. Altemani A, Martins MT, Freitas L et al. Carcinoma ex pleomorphic adenoma (CXPA): Immunoprofile of the cells involved in carcinomatous progression. Histopathology. 2005;46:635-641.

6. Harada H. Histomorphological investigation regarding to malignant transformation of pleomorphic adenoma (so-called malignant mixed tumour) of the salivary gland origin: special reference to carcinosarcoma. Kurume Medical Journal. 2000;47:307-323.

7. Olsen KD, Lewis JE. Carcinoma ex pleomorphic adenoma: a clinicopathologic review. Head Neck. 2001;23:705-712. 
8. Peel RT, Gnepp DR. Diseases of the salivary glands. Leon Barnet (Ed.), surgical pathology of the head \& neck, Marcel Dekker, New york. 1985:593-596.

9. Aker H, Ozturk M, Ozec I, Ozer H. A usual buccal adenoma with extensive squamous metaplasia and cyst formation $\mathrm{J}$ Chin Med Assoc. 2003;66:184-188.

10. Donath K, Seifert G. Tumour stimulating squamous cell metaplasia (SCM) in necrotic area of salivary gland tumours Pathol Res Pract. 1997;193:689-693.

11. Masamichi I, Kenichiro U,Hitoshi N,Toshikazu G,Kohsuke S,Yoshiya U. A squamous cell carcinoma ex pleomorphic adenoma in the palate: Immunohistochemical analysis and chromosomal alteration by comparative genomic hybridization. Oral Oncology Extra. 2005;41(8):170-173.

12. Meyers EN, Ferris RL. Salivary gland disorders. Ed. Springer. 2007:65-67.

13. Barnes EL, Everson JW, Reichart P, Sidransky D. Tumours of the salivary glands. In: World health organization, classification of tumours: Pathology \& genetics of head \& neck tumours. Lyon; IAR. 2005:209-281.

14. Antony J. Gopalan V, Smith RA et al. Carcinoma ex pleomorphic adenoma: a comprehensive review of clinical, pathological and molecular data. Head \& neck pathology. 2012;6:1-9.

15. Steele NP, Wenig BM, Sessions BW. A case of pleomorphic adenoma metastasizing to a mediastinal lymph node. Am J Otolaryngol. 2007;28:130-133.

16. Lewis JE, Oslen KD, Sebo TJ. Carcinoma ex pleomorphic adenoma- pathological analysis of 73 cases. Hum Pathol. 2001;32(6):596-604.

17. Xin W, Paulino AF. Prognostic factors in malignant tumours of the salivary gland: Correlation of immunohistochemical markers with histologic classification. Ann Diagn Pathol. 2002;6(4):205-210. 